\title{
Institutions of international energy cooperation in North-East Asia region
}

Konstantin Korneev", and Anatoly Korneev, Melentiev Energy Systems Institute of Siberian Branch of the Russian Academy of Sciences, Irkutsk, Russia

\begin{abstract}
The article deals with the problems of international energy cooperation (IEC) development in North-East Asia region (NEA). There is a process of gradual formation of common regional energy markets, which requires the improvement of international cooperation institutions. At the moment this process is in early stage, but the experience of such integration structures as the European Union and NAFTA (North American Free Trade Agreement) demonstrates that energy cooperation can be effective and beneficial to all participants. The countries of NorthEast Asia need to develop international electricity grids and natiral gas pipelines, which stimulates the evolution of common energy markets institutions with the active participation of both government bodies and private energy companies. Keywords: energy cooperation, energy policy, institutions, North-East Asia region.
\end{abstract}

\section{Introduction}

In 2006-2008, a research project "Understanding International Energy Initiatives" was carried out at the Asia Pacific Energy Research Centre (APERC). The tasks of this project were to classify and evaluate the effectiveness of international energy cooperation institutions in the APEC region. In addition, there were considered the prospects for the development of these institutions at the stage from joint research projects in the field of energy technologies to solving practical problems in the construction of interstate energy infrastructure [1].

The purpose of this article is to update the results of the APERC study with the allocation of new directions and prospects for international energy cooperation in NorthEast Asia. The NEA region was chosen as a target not only because of its geographical proximity to Russia. The extension of cooperation with the economies of North-East Asia as a result of the Russian government's policy to diversify economic ties is on the agenda now. North-East Asian countries have mature economies and are predictable and stable partners. In addition, the strengthening of cooperation with the states of this region will greatly contribute to the development of the Russia's eastern regions, which have

\footnotetext{
* Corresponding author: kor_inf@isem.irk.ru
} 
significant natural resources and undeveloped territories, but do not have enough opportunities to invest in the construction of new energy infrastructure.

The purpose determines tasks:

a) assessment of the current status of international energy cooperation in the region;

b) analysis of energy cooperation institution development, taking into account the country-specific in North-East Asia;

c) consideration of the prospects for IEC in North-East Asia, taking into account economic and political risks.

The strengthening of international energy cooperation is inevitable, as the traditional tasks of ensuring energy security and efficient use of energy resources are complemented by the increasing need to protect the environment through the introduction of new energy technologies, the development of which by each country separately requires significant resources. North-East Asia is currently a driver of global economic growth and will remain so in the future. Therefore, the issue of formulating a common vision for the long-term development of energy sector is relevant for the countries of the region, since the inconsistency of regional energy policy in the future will prevent the creation of international energy infrastructure.

\section{The main institutions of energy cooperation in the NEA region at the moment}

The current state of multilateral cooperation in the NEA region in the energy sector is hardly satisfactory. North-East Asian countries have different approaches to the development of national and international energy markets, which makes it difficult to communicate on these issues. However, since the late 1990s there has been an increasing interest to the problems of IEC (for example, the Asia Super Grid project), which was caused by both the financial and economic crises of 1998 and 2008, and also relied on the successful experience of the EU countries in this area [2].

The following basic institutions of international energy cooperation in North-East Asia region can be distinguished:

1. Organizing the interstate structures aimed at $R \& D$ in the field of urgent problems of energy supply. An example is the North-East Asian Gas and Pipeline Forum (NAGPF), organized in the mid-1990s with the active participation of Melentiev Energy Systems Institute SB RAS, and also research institutes from China, Japan, Mongolia, Republic of Korea. The purpose of the Forum is to carry out joint scientific and research works, and to elaborate policy recommendations on the development of transportation infrastructure in North-East Asia for governments and international organizations [3].

2. Creation of intergovernmental organizations to coordinate efforts in the construction of energy infrastructure and, in the future, the management of the common energy markets. The most successful example is the Trans-ASEAN Gas Pipeline Project (TAGP). The goal is to ensure the security of natural gas supplies in the ASEAN region by integrating existing national gas supply systems into a single regional gas transportation network. By 2015, 13 pipelines with a total length of 3,631 km had been constructed under TAGP [4].

3. Assessment of risks and barriers to energy cooperation in the NEA region. This assessment is provided by research institutes of all countries of North-East Asia, however, the focus on national markets prevails. For the most part, the expert community recognizes international energy cooperation in North-East Asia as a promising area. The key factors of success are the need to unify energy standards and equipment along with overcoming political contradictions between the countries of North-East Asia, emerged as a result of the conflicts of the twentieth century [2]. 
It should be noted that the main drivers of IEC are governments and other state structures with significant financial and administrative resources. In order to attract new participants, for example, private energy companies, it is necessary to assess how the potential benefits and costs for ones relate to similar situations for others.

The joint participation of the government and business is a good tool for the development of international energy cooperation institutions. It is possible to take advantage of each participant, but at the same time it is not expected that the benefits will be the same for all. This means that the energy initiatives announced by the governments should take into account the interests of the energy business, which do not always coincide with the interests of the authorities. Governments, in addition to making profits and entering new markets (which is a priority for business), expect to receive non-market (political, image) effects from energy cooperation.

In this case, it is assumed that the business will allocate financial and intellectual resources in exchange for the opportunity to expand business activity. On the other hand, the energy business will count on government support if the international energy infrastructure development projects proposed by it do not lead to a rapid return on investment, but lies in the sphere of state interests [5]. Thus, different ways of benefiting from international energy cooperation will be a problem until the participants themselves recognize this asymmetry and work out ways to overcome it.

\section{Analysis of energy cooperation institutions in North-East Asia countries}

There are a lot of IEC institutes, which is confirmed by the results of the APERC research. Section 2 lists the main ones, but their success requires an appropriate institutional environment that establishes rules of conduct for all participants in international cooperation. Let us consider the necessary conditions for the formation and development of such institutions:

1. The presence of several participants in the energy cooperation process. National governments and businesses related to energy sectors play key roles in the international energy cooperation, but there are other important actors. The interaction of all participants forms the environment necessary for the successful implementation of the cooperation ideas. Additional participants may include organizations engaged in energy technology R\& $\mathrm{D}$, the media, and various non-profit organizations dealing with related issues, such as ecology or environmental management. It is unreasonably to underestimate the role that additional participants play. They have levers of influence on public opinion with respect to a particular energy project, and under certain circumstances can prevent implementation of these projects [6].

Interstate infrastructure projects in the field of energy are complex and time-consuming, so the most indicative when demonstrating the interaction of all participants in the process of energy cooperation. The Trans-ASEAN Gas Pipeline Project (TAGP) and the North-East Asian Gas and Pipeline Forum (NAGPF) discussed above as examples confirm this by their activities. Cooperation on TAGP is based mainly on the political positions of regional governments and the practical interest of business, but a well-thought-out strategy of interaction with the media and NGOs of environmental orientation has largely created a positive information background around this structure [4].

The emergence of NAGPF, on the other hand, was driven by the interests of the energy business, which felt the potential of the common gas market in East Asia. Large reserves of natural gas are available in Eastern Siberia and Central Asia, and consumption centers are located in China and Japan. There are no technical problems to build up the interstate network of pipelines, it remains only to solve the issues of investment and reduce political 
risks. The basis of NAGPF activities is R\&D, with minimal support from governments and energy companies, so research centers from Russia, Japan, China, Mongolia and the Republic of Korea cooperate on an equal platform. This sets a steady trend for deepening international cooperation in the scientific and expert framework, which ultimately prepares the ground for multilateral negotiations on the development of gas markets in the NEA region at the governmental level [3].

2. Quantitative and qualitative changes in the energy cooperation process. International cooperation in the field of energy is a complex organism, equally prone to ups and downs. For example, the process may be suspended if the mechanisms for achieving the goals are ineffective, or the ultimate aims of cooperation cease to meet the changed conditions. In order to launch the mechanisms again, institutional changes are needed that may relate not only to legal regulation but also to changes in the composition and number of participants in IEC. If the guarantors of cooperation - national governments - are interested in such changes, the process can be resumed under new conditions and lead to new results [6].

Thus, changes in the institutions of international energy cooperation occur both as a result of external factors and in case of internal problems. At any time participants of the process may face similar circumstances, although to varying degrees. The usual decisionmaking procedures at the governmental level are sometimes insufficient to change institutions or clarify the objectives of cooperation. Comprehensive long-term international projects, such as the Energy Charter Treaty (ECT), can take advantage from the special opportunities included during the establishment, which allow at the working level to review and modernize cooperation institutions, and to discuss the results of such revision at seminars and conferences [5].

These built-in mechanisms of adaptation to changing conditions are important for the sustainability of IEC, especially in the North-East Asian region, suffering from the absence of common economic space like that formed within the EU. Periodic evaluation of the effectiveness of institutional factors should be an integral part of the international cooperation process, and participants should be able to lobby for these changes at the highest level. Such a built-in mechanism for periodic reassessment and modification of institutions is a platform for the successful and long-term international energy cooperation.

3. Successful implementation of the energy cooperation process depends on the effectiveness of mechanisms that created to manage it. This requires the presence of three elements: the involvement of high-level representatives; the availability of adequate financial resources; effective coordination of work within the organization. The lack of any of these three elements can lead to stagnation of energy cooperation. In other words, it goes into a stage that lasts indefinitely at the lowest possible level of activity, and does not require significant resources to maintain its existence. Later, when external circumstances change or the need arises, cooperation can be easily restarted [5].

The involvement of high-level representatives means direct participation of the government or business structures and contributes to the effective functioning of the IEC institutions. The presence of a motivated leader can help to overcome the periods when participants lose interest to interact, and stimulate their determination to achieve declared purposes.

The availability of financial resources follows from the involvement of officials in the process of international energy cooperation. In the countries of North-East Asia it is particularly important because the system of informal relations between different groups historically quite strong. The endorsement and support of influential people often plays a crucial role in launching MEA mechanisms and providing them with the necessary political weight.

However, in order to obtain the necessary resources, any joint energy project at the beginning of its life cycle must prove the uniqueness of the goals and mechanisms to achieve them; to provide a detailed assessment of the expected positive effect. Moreover, the emergence of a sustainable interest to the project requires effective coordination 
between both national and international levels of participation, as well as a clear understanding of the rights and obligations of all participants of energy cooperation $[2,6]$.

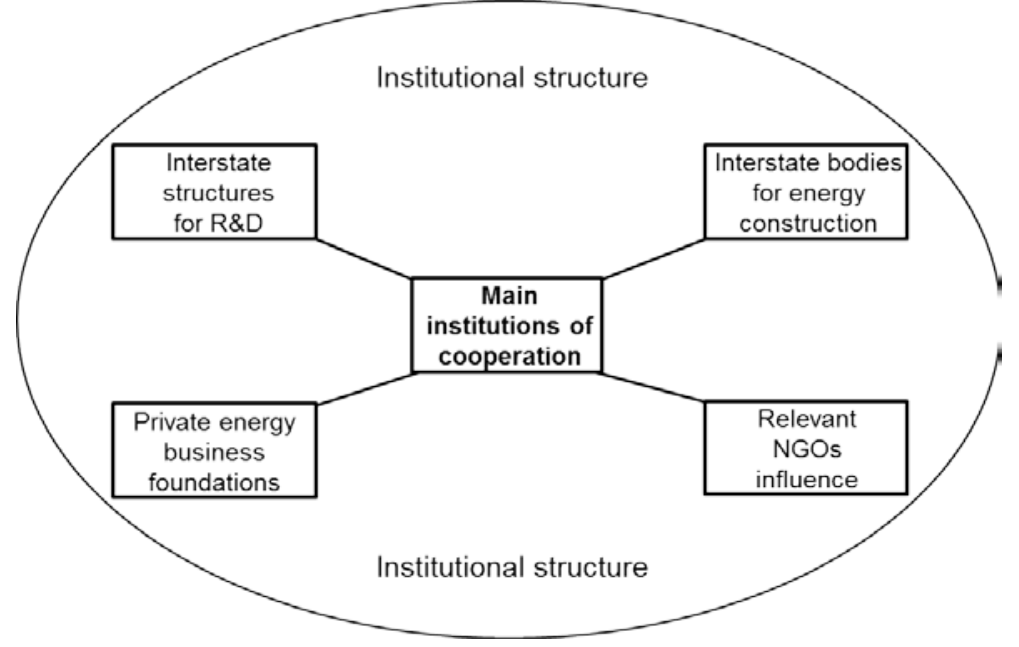

Fig. 1. Main institutions of energy cooperation

\section{Prospects for energy cooperation in North-East Asia region}

International energy cooperation is a relatively new way of interaction for the countries of North-East Asia. However, for two decades since the end of the 1998 Asian financial crisis, there has been a steady interest in the development of common energy markets. Multilateral agreements are being concluded and methods of cooperation are being improved. However, some parts of energy sector are more suitable for cooperation than others.

For example, as the need for peaceful uses of nuclear energy would increase, active international cooperation was particularly useful for the development of nuclear power. The idea of creating an international regime for energy investment along its entire chain, from the extraction of primary energy resources to their delivery to the final consumer, also has a good potential [7].

It should be noted that the prospects for IEC in the North-East Asia region are often not very optimistic due to underdeveloped institutions and lack of elaboration of cooperation mechanisms. This is partly due to attempts to combine the large scale of the certain energy problem with the limited possibilities of the mechanisms currently available to the participants in the cooperation process. Additional difficulties lie in the contradiction between the unspoken rules of international markets and the national legislation of separate countries [6].

As a result, some projects of international energy cooperation in the NEA region, examples of which are given above, achieve good results but have limited impact; it is problematic to use their mechanisms in relation to a wider range of participants. This is confirmed by the rapid growth in the number of "soft "cooperation institutions, such as staff improvement and information exchange in the framework of round tables, and the lack of "hard" ones, such as development and implementation of a unified legal framework for all participants [5].

The Asia-Pacific Economic Cooperation (APEC), established in 1989, is an example of sustainable international cooperation in the NEA region. The organization is composed 
of 21 States, including all countries of North-East Asia. APEC economies account for about $40 \%$ of the world's population, about $54 \%$ of GDP, and $44 \%$ of world trade.

APEC does not have a charter and a rigid organizational structure, but contributes to the establishment of a common legal framework that stimulates the development of international markets and is organically supplemented by relevant laws at the national level [8]. Perhaps this format of interaction will be the most appropriate for the North-East Asia countries and will allow forming sustainable international energy cooperation institutions in the future.

\section{Implications}

It should be understood that there are a lot of ways to solve specific problems of energy supply and energy saving in addition to the institutions of international energy cooperation. For those areas of energetics where potential for the effective use of such institutions can be determined, the targeted establishment of a special enabling legal regime may be required. The implementation of such regime, unfortunately, is currently out of the question in NEA countries [7]. For example, economies that have made great strides in addressing energy supply and conservation issues (mainly Japan and the Republic of Korea) are not too eager to share their knowledge and technologies in this area. Therefore national governments and business structures should set realistic goals and continue to regularly re-evaluate the capacity of IEC institutions to achieve these goals.

\section{Acknowledgements}

This publication was prepared under the project of fundamental research of SB RAS AAAA-A17-117030310434-3

\section{References}

1. S. Popov, D. Fedor. Understanding International Energy Initiatives in the APEC Reg ion. Tokyo, Asia Pacific Energy Research Centre, 99 p. (2008)

2. P. Aalto. Energy market integration and regional institutions in East Asia, Energy Policy, vol. 74, pp. 91-100 (2014)

3. Kazuhiko O'Hashi. Activities to realize regional energy and environmental security by Northeast Asian Gas \& Pipeline Forum (NAGPF). Available at: https://www.erina.or.jp/wp-content/uploads/2014/10/ohashi.pdf

4. A.Setiawan, A.Shahroom. The complexities of programmme management: case study Trans-ASEAN Gas Pipeline, PM World Journal, vol. 5, pp. 1-17 (2016)

5. S. Popov. The institution of international multilateral cooperation in the energy sector: APEC experience. Energeticheskaya politika, N. 3, pp. 60-70 (2013)

6. P.Aalto. Institutions in European and Asian energy market: a methodological overview, Energy Policy, vol. 74, pp. 4-15 (2014)

7. Vivoda V. Evaluating energy security in the Asia Pacific region: a novel methodological approach. Energy Policy, vol. 38, pp. 5258-5263 (2010)

8. APEC Economic Policy Report: Structural Reform and Human Capital Development. APEC secretariat, Singapore, 75 p. (November 2017) 